\title{
On farm research is a viable means of technology verification, dissemination and adoption: a case of wheat research in Nepal
}

\author{
KP Timsina ${ }^{1}$, S Gairhe ${ }^{2}$, DB Thapa Magar ${ }^{1}$, YN Ghimire ${ }^{1}$, D Gauchan ${ }^{3}$ and Y Padhyoti ${ }^{4}$ \\ ${ }^{1}$ Socio-economic and Agriculture Research Policy Division, Khumaltar, ${ }^{2} \mathrm{Nepal}$ \\ Agricultural Research Council, Singh Durbar, ${ }^{3}$ Bioversity International, ${ }^{4}$ Ministry of \\ Agriculture Development, Nepal \\ Email: krishnatimsina2000@gmail.com
}

\begin{abstract}
A study on the role of on-farm/outreach research (OR) site in wheat technology dissemination was conducted in Terai regions of Sunsari, Rupandehi and Banke districts, Nepal. On-farm research sites representing irrigated, partially irrigated and rainfed production domains and their comparative control, the non-outreach research sites were selected. From the list of wheat growers in respective study sites, 30 samples from each of the VDCs were selected randomly irrespective of their landholdings with the total sample size of 180 for the study. The study revealed that overall area covered by the improved varieties was about 94\%; however, it was $100 \%$ in OR site. The area covered by the improved varieties released after 1990s was found higher in OR site but there was still domination of improved variety Nepal 297 in the study area, which was released in 1985. The Technological Adoption Index (TAI) for wheat was found higher (0.63) in OR site compared to non-OR site (0.43). Test for equality of mean of TAI was carried out between $\mathrm{OR}$ and non-OR sites and found significantly different $(\mathrm{P}=<0.000)$ between the sites. Farmers were categorized into low adopters, medium adopters and high adopters based on their TAI value after conversion into percentage. Chi-square test shows the significance difference $\left(\chi^{2}=24.82\right.$ and $\left.\mathrm{P}=<0.000\right)$ in number of farmers in different adoption categories between OR and non-OR sites. Results indicate OR sites are playing viable role for increasing number of high adopters (farmers) compared to non-OR site farmers. The knowledge on good agriculture management, access to modern improved seed, and use and availability of agriculture information, availability of agricultural inputs and loan were found significantly high on OR sites. There exists large scope for yield improvement of the wheat in Nepal by increasing number of outreach sites and by strengthening institutional coordination and linkage among the related stakeholders at different levels to provide system based packages rather than component technology for mass dissemination and adoption of technology among the farmers at large.
\end{abstract}

Keywords: on-farm research, TAI, technology dissemination, system based packages 


\section{Introduction}

Dissemination of wheat technologies during green revolution played critical role in improving food security and reducing poverty in many developing countries (Evenson and Gollin, 2003). In the early stage of the green revolution high yielding semi-dwarf varieties of wheat were developed and disseminated in many parts of world including part of Nepal Terai. The return from wheat research and dissemination of improved varieties in Nepal was very high during both green revolution and post -green revolution period (Morries et al; 1994). On-farm or outreach research activities in wheat played critical role in technology validation and dissemination in Nepal.

After realization of traditional discipline and commodity oriented research system is not enough to address complex farmers' problems in major food crops including in wheat during green revolution, on-farm research was initiated to address priority technological needs of farmers by identifying one outreach site in command area of each research stations in late eighties in Nepal (Vaidya, 1996). Outreach research activities have been implemented by Nepal Agricultural Research Council (NARC) in more than 50 outreach research (OR) sites through Regional/Agricultural Research Stations (R/ARS) in various agro-ecological domains across the country (ORD, 2009). These activities are designed and implemented to validate station generated technologies and up-scale promising technologies in farmers' fields. However, the information on the role of outreach research in technology dissemination in the country is not well assessed and documented.

On-farm or Outreach research (OR) is conceived and defined in different ways. Outreach research program (ORP) is mainly referred to the on-farm adaptive research conducted with farming system perspective in close coordination with the farmers and extensionists. It provides venue for the technology generators, technology disseminators and the clients to work together from the beginning of problem identification to program implementation and evaluation (Vaidya, 1996). Farmer-participatory research can help improve the effectiveness of technology development, increase the payoff to agricultural research and raise adoption rates (Freeman, 2001). McIntyre et al (2009) reported that collaborative approaches and methods have added value to the encounter between formal agricultural knowledge, science and technology (AKST) actors and traditional/local knowledge actors. Gauchan et al (2003) emphasized broadening the role of outreach research from narrow focus of on-farm testing, validation and promotion of station generated technologies to wider role of coordinating, networking and supporting a broad range of participatory technology development (PTD) and promotional activities inside and outside of NARC. The PTD approach in different countries shows its contribution to improve agricultural extension and training, led to increased yields of major crops. Also, the higher incomes contributed to improved food and nutrition security (Wettasinha et al; 2014). The newly identified varieties are released faster in several Asian and North African countries through participatory plant 
breeding compared to the conventional breeding system, and most importantly the results are better adapted to the farmer's needs and environment (Ceccarelli and Grando, 2007).

Paudel et al (2007) reported OR sites are the meeting point for the technology verification where all the stakeholders come together and extension agencies are supposed to take finetuned technologies for wider dissemination from OR sites (Paudel, 2013). NARC has given priority to enhancing capacity of research systems to critically evaluate the relevance, acceptability and competitiveness of generated technologies (Gauchan and Pandey, 2005). Currently, technology integration and packaging part of outreach is not very strong due to conventional disciplinary focus of research on technology generation and validation rather than integration, packaging and up-scaling using holistic interdisciplinary and system framework (Gauchan, 2008). Most of the service providers are still providing component technology to farmers rather than its complete technological packages. The Technological Adoption Index (TAI) is a catch-all measure of technology adoption practices of the farmers (Singh et al; 2005 cited in Timsina et al; 2012b). Modern varieties could contribute in the area expansion of the crop due to higher productivity and profitability (Shrestha et al; 2012) but only dissemination of improved varieties cannot provide potential yield, it should be grown with applying recommended dose of fertilizers and irrigation at appropriate time to increase Technological Adoption Index (TAI) (Timsina et al; 2012b). On this background, this study was carried out to find out role of OR program in transfer of wheat technology to increase TAI in Terai region of Nepal.

\section{Methodology}

\section{Selection of study sites and sample}

This study was confined in Terai region of Nepal in 2012 since NARC has major OR focus in Terai region which represents about 59\% of wheat area in Nepal (MoAC, 2011). Sunsari, Rupandehi and Banke districts were selected purposely representing Eastern, Western and Mid-western terai regions because they represent the major wheat growing areas of the selected regions (Sunsari represents $21 \%$ of eastern terai's wheat area, Rupandehi represents $39 \%$ of western terai's wheat area and Banke represents $36 \%$ of midwestern terai's wheat area) (MoAC, 2011) and have presence of outreach research sites of NARC. Outreach research sites representing irrigated, partially irrigated and rainfed production domains were selected purposely from Rupandehi, Sunsari and Banke, respectively after discussion with officials from National Wheat Research Program, Rupandehi; Regional Agriculture Research Station, Tarahara; and Regional Agriculture Research Station, Khajura. Nonoutreach sites from respective production domains were selected purposely based on their comparative control after discussing with respective District Agriculture Development Offices (DADOs). From the list of wheat growers in respective study sites, a total of 180 sample farmers were selected randomly covering 30 samples from each of the VDCs from 
both outreach and non-outreach sites. The summary of the site selection and sampling technique is presented in Table 1.

Table 1. Details of study area and sampling

\begin{tabular}{|c|c|c|c|c|c|}
\hline District & Domains & VDCs & Sample Size & Methods & \\
\hline $\begin{array}{l}\text { Sunsari } \\
\text { Irrigated }\end{array}$ & Partially & $\begin{array}{l}\text { Simaria-Outreach Site } \\
\text { Sattarjhoda-Non } \\
\text { outreach site }\end{array}$ & $\begin{array}{l}30 \text { from each outreach } \\
\text { and non-outreach site }\end{array}$ & $\begin{array}{l}\text { Purposive } \\
\text { Simple } \\
\text { sampling }\end{array}$ & $\begin{array}{r}\text { and } \\
\text { random }\end{array}$ \\
\hline \multirow[t]{2}{*}{$\begin{array}{l}\text { Rupandehi } \\
\text { Irrigated }\end{array}$} & & $\begin{array}{l}\text { Mahilwar- Outreach } \\
\text { site }\end{array}$ & $\begin{array}{l}30 \text { from each outreach } \\
\text { and non-outreach sites }\end{array}$ & $\begin{array}{l}\text { Purposive } \\
\text { Simple }\end{array}$ & $\begin{array}{r}\text { and } \\
\text { random }\end{array}$ \\
\hline & & $\begin{array}{l}\text { LumbiniAdarsha non } \\
\text { outreach site }\end{array}$ & & sampling & \\
\hline $\begin{array}{l}\text { Banke } \\
\text { Rainfed }\end{array}$ & & $\begin{array}{l}\text { Puraina-Outreach Site } \\
\text { Katkuhiya-Non } \\
\text { outreach site }\end{array}$ & $\begin{array}{l}30 \text { from each outreach } \\
\text { and non-outreach site }\end{array}$ & $\begin{array}{l}\text { Purposive } \\
\text { Simple } \\
\text { sampling }\end{array}$ & $\begin{array}{r}\text { and } \\
\text { random }\end{array}$ \\
\hline
\end{tabular}

\section{Method of data collection and analysis}

Different techniques such as household interview, group discussion, and informal interaction with the farmers in the study area were carried out for primary information collection. The data were compiled, reviewed and cleaned before final analysis for the accuracy of the results. This study used both descriptive statistics such as mean, frequency, standard deviation and inferential statistics such as independent t test, chi-square test. Moreover to know the adoption pattern of improved technologies, the adoption index was used, the details of which is given below.

\section{Adoption index}

The technology adoption practices include area under high yielding varieties (HYVs), appropriateness of irrigation level and dosage of fertilizers. The technology adoption can be computed by using following formula (Singh et.al, 2005 cited in Timsina et al; 2012b) which was fitted for our study purpose.

$\mathrm{TAI}_{\mathrm{i}}=\frac{1}{5}\left[\frac{A H i}{C A i}+\frac{N A i}{N R i}+\frac{P A i}{P R i}+\frac{I A i}{I R i}+\frac{K A i}{K R i}\right]$

Where,

$\mathrm{i}=$ Number of farmers, say $1,2,3, \ldots ., \mathrm{n}$.

$\mathrm{TAI}_{\mathrm{i}}=$ Technology Adoption Index of $\mathrm{i}^{\text {th }}$ farmer

$\mathrm{AH}_{\mathrm{i}}=$ Area under modern wheat varieties (ha)

$\mathrm{CA}_{\mathrm{i}}=$ Total area of wheat (ha)

$\mathrm{NA}_{i}=$ Quantity of nitrogen applied for wheat $(\mathrm{kg} / \mathrm{ha})$

$\mathrm{NR}_{\mathrm{i}}=$ Recommended dose of nitrogen of wheat $(\mathrm{kg} / \mathrm{ha})$

$\mathrm{PA}_{\mathrm{i}}=\mathrm{Quantity}$ of phosphorus applied for wheat $(\mathrm{kg} / \mathrm{ha})$

$\mathrm{PR}_{\mathrm{i}}=$ Recommended dose of phosphorus of wheat $(\mathrm{kg} / \mathrm{ha})$ 
$\mathrm{IA}_{\mathrm{i}}=$ Actual number of irrigation applied in wheat during crop cycle

$\mathrm{IR}_{\mathrm{i}}=$ Recommended number of irrigations during wheat crop cycle

$\mathrm{KA}_{\mathrm{i}}=$ Actual amount of potash applied for wheat $(\mathrm{kg} / \mathrm{ha})$

$\mathrm{KR}_{\mathrm{i}}=$ Recommended amount of potash applied for wheat $(\mathrm{kg} / \mathrm{ha})$

This index was used to analyse the adoption level of wheat growing farmers. In order to calculate fertilizer dose, the fertilizer used quantity was converted into elementary form. The mean TAI between OR and non- OR sites were tested by using independent sample test.

\section{Chi-square test}

This test was used to see the difference in different technological aspects such as access to modern varieties, easy availability labor, availability of loan, knowledge on modern agriculture technology, and use and availability of agriculture information between OR and non-OR sites. Moreover, it was also used to analyse adoption categories between OR and non-OR sites.

\section{Results and discussion}

\section{Socio economic condition in the study area}

In the study area, the average age of the respondent was found 47 year. The average household members per household were 7.9, which are more than the national average of 4.4 (GoN/MoHP, 2011). Only about 20\% upland was found irrigated which is far below than irrigated lowland. About $23 \%$ farmers were cultivating wheat in unirrigated land (Table 2).

Table 2. Socio-economic characteristics of the study area

\begin{tabular}{ll}
\hline Variables & Description \\
\hline Average Age of respondent (year) & 47 \\
Average Household member & 7.9 \\
Irrigated lowland \% & 93 \\
Irrigated Upland \% & 20 \\
Wheat cultivated in unirrigated land \% & 23 \\
\hline
\end{tabular}

\section{Area coverage by wheat varieties}

In order to increase the productivity, thirty four wheat varieties have been released with the package of practices for different agro-ecological regions in Nepal (NWRP, 2014). About 94\% wheat area was covered by seven modern varieties; Nepal 297, Gautam, Bhirkuti, Vijay, Aditya, RR-21 and BL 1473 in the study area. However, it was 100\% in Sunsari and Rupandehi areas; only about $6 \%$ area was covered by two local varieties in Banke area. We had also separated modern varieties released before and after 1990s considering 
establishment of NARC in 1991. Area covered by modern varieties released after 1990s was about 32\%. Among the modern wheat varieties, Nepal 297, released in 1985 (CPDD, 2014), was still a dominant variety adopted in $64 \%$ of terai area of Nepal. Shrestha et al (2012) reported about $98 \%$ to $100 \%$ wheat area was covered by modern varieties in terai with dominance of Nepal 297 ranges from $30 \%$ to $60 \%$ in different terai region of Nepal. Similarly, MoAD (2013) reported $100 \%$ coverage of wheat modern varieties in terai region of Nepal. However, our study indicates some terai areas were still using traditional varieties.

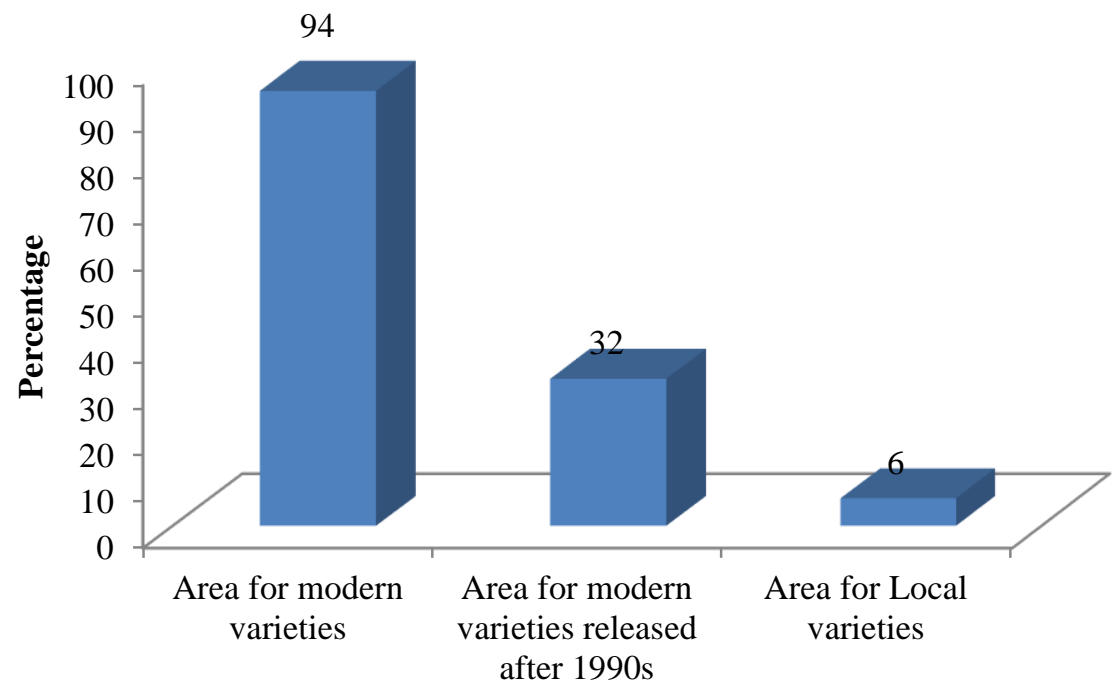

Figure1. Area coverage by different varieties categories in the study area

Assuming $100 \%$ for given area coverage to different types of wheat varieties presented in Figure 1, we calculated area coverage of different types of wheat varieties for OR and nonOR sites. Area covered by both modern wheat varieties released before 1990s and modern varieties released after 1990s was found higher in OR sites compared to non- OR sites. None of the traditional varieties were used in OR site; only farmers residing in non-OR site of Banke area were cultivating traditional varieties such as Setobala and Sabna. In both OR and non-OR sites, Nepal 297 was found dominant followed by Gautam. 


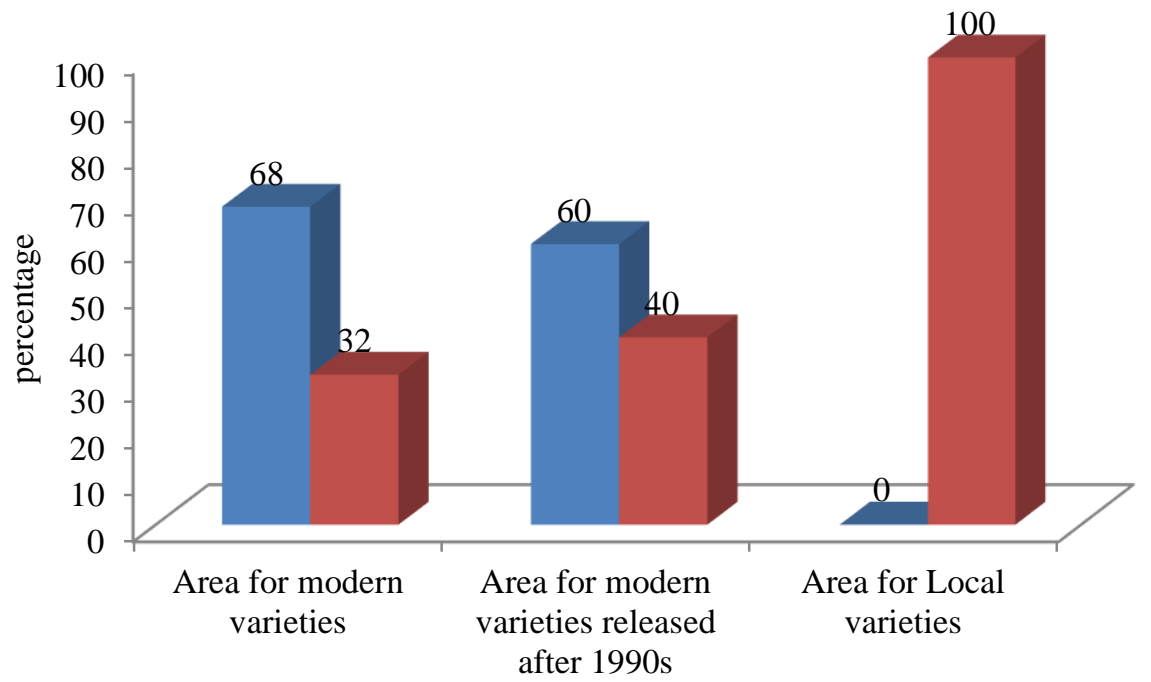

\section{Figure 2. Area coverage by different variety categories in the OR and non-OR sites}

The finding indicates that yield of Nepal 297 is relatively higher than other varieties. Other varieties such as Gautam and Vijaya were also providing similar yield compared to Nepal 297 in the study area. Nepal 297 is late sowing short duration (117 maturity days) variety (CPDD, 2014) suitable for existing rice-wheat cropping system and they want to continue this variety which was earlier adopted. For example Radha-12 is most popular rice variety in terai of Nepal (Timsina et al; 2012b; Shrestha et al; 2012 and Witcombe et al; 2009) which takes 155 maturity days (CPDD, 2014), so to fit in existing rice wheat cropping system, farmers were choosing Nepal 297 even though this variety is already recognized as unsuitable by Government due to yellow rust susceptibility in areas with high humidity and winter temperature between 8 to 18 degree Celsius (The Himalayan Times, 2007). SARPOD (2014) reported Nepal 297 would allow time for growing sugarcane without reducing its yield. Ponzio et al (2013) reported that the farmers may not always prefer the highest productive varieties; rather they preferred the other characteristics which they required in their farming system.

\section{Fertilizers use and irrigation application}

In the study area, average use of Nitrogen, Phosphorus and Potash was found $60 \mathrm{~kg} / \mathrm{ha}, 46$ $\mathrm{kg} / \mathrm{ha}$ and $23 \mathrm{~kg} / \mathrm{ha}$, respectively. This was calculated through conversion of Urea, DAP and MoP into the elementary form. The average quantity applied was slightly lower than the national recommendation, which is 100,50 and $25 \mathrm{~kg} / \mathrm{ha}$ for $\mathrm{N}, \mathrm{P}$ and $\mathrm{K}$, respectively (AICC, 2015). However, the quantity of N, P, K application was found higher than national recommendation in Rupandehi. The use of $\mathrm{N}, \mathrm{P}$ and $\mathrm{K}$ was found higher in OR site compared to non-OR site. None of the farmers in non-OR site of Banke were using $\mathrm{K}$ 
in their wheat field. Joshi (2010) reported about on average 40:20:4 kg NPK per hectare has been used by rice farmers in Banke and Nawalparasi districts. The average number of irrigation application during the cropping cycle was found lower than the recommended. For higher yield, water should be provided for 5 times of wheat crop cycle (FAOSTAT, 2001). The number of irrigation application in OR sites was also found higher than nonOR sites (Table 3). Timsina et al (2012b) reported lower fertilizers and irrigation application compared to national recommendation in case of rice in Terai condition of Nepal. If the area under irrigation for rice cultivation is increased, the farmers would also increase fertilizer use. This is because the purchase of fertilizer includes cash expenses and farmers may find its use more profitable under irrigated condition compared to rainfed as it has synergistic effect on the productivity (Joshi, 2010). ORD (2009) reported the attainable yield of wheat is around 4 ton/ha and the national average is around 2 ton/ha. This indicates a wide gap between attainable yield and farmers yield in wheat crop. Wheat yields suffer from the factors such as lack of reliable irrigation, fertilizers, inclement weather and lack of improved technology. The growth of wheat production was disappointing in some years, averaging $1.7 \%$ per annum during 2002-2006 and the average yield of 1.93 tone/ha (MoAC, 2009) in Nepal was low by South Asian Regional standards. During the last 3 decades, average farm yield of wheat increased from $1181 \mathrm{~kg} / \mathrm{ha}$ to $2496 \mathrm{~kg} / \mathrm{ha}$ (111\%) (MoAD, 2014). But it is far below than attainable yield. NWRP (2014) reported there is still need to increase production of wheat either from increased productivity or by bringing rice fallow into wheat cultivation with increase in irrigation and other support system.

Table 3. Use of fertilizer and irrigation in the study area

\begin{tabular}{lllll}
\hline & \multicolumn{2}{l}{ Use of fertilizer $\mathbf{( k g / h a )}$} & Irrigation \\
\cline { 2 - 4 } Study sites & $\mathbf{N}$ & $\mathbf{P}$ & $\mathbf{K}$ & applied (no.) \\
\hline OR & 65.9 & 47.1 & 23.3 & 2.2 \\
Non OR & 53.7 & 44.5 & 22.7 & 1.4 \\
Average & 59.8 & 45.8 & 23.0 & 1.8 \\
\hline
\end{tabular}

Adoption of new technology implies using entire package of practices for the cultivation of improved wheat varieties. Adoption of HYVs is only one aspect of achieving higher yields. There are other factors which influences the yield per unit area of any crop. An adoption index was calculated for individual farmers, which include the adoption of improved varieties, adoption of recommended doses of chemical fertilizers ( $\mathrm{N}, \mathrm{P}$ and $\mathrm{K}$ ), and number of irrigation applied. The overall TAI for wheat was found 0.54. Among different technological inputs, number of irrigation applied was found critical to obtain lower TAI. Timsina et al $(2012 \mathrm{~b})$ reported $0.49 \mathrm{TAI}$ for rice in Terai region of Nepal. The result indicates large scope for yield improvement of the wheat in the study area due to its lower TAI. Shrestha et al (2013) reported the gap between potential yield and on-farm yield of 
wheat in different ecological regions. He suggested based on the potentiality of pipeline technologies, the wheat productivity was anticipated to increase by 10 per cent each in the eastern and central regions and by 20 per cent in the western region in the next ten years. It was because the soil of western region has not been exploited with higher inputs as compared to the eastern and central regions (Shrestha et al; 2013).

The TAI for wheat was found higher (0.63) in OR sites compared to non-OR sites (0.43). The results indicates that more number of wheat farmers in OR sites were using entire package of practices compared to non-OR sites. Test for equality of mean was carried out by using independent $\mathrm{t}$ test between $\mathrm{OR}$ and non-OR sites and found significant different $(\mathrm{P}=0.000)$ between the sites (Table 4$)$.

Table 4. Average Technology adoption Index (TAI) by OR and non- OR sites

\begin{tabular}{lcc}
\hline Description of study area & TAI & \\
\hline OR site & 0.63 \\
Non OR site & 0.43 \\
Overall & $0.54 * *$ \\
\hline
\end{tabular}

Note: $* *$ Mean difference $0.20, \mathrm{df}=148, \mathrm{P}=0.000$

The farmers were categorized into three group's i.e low adopters, medium adopters and higher adopters based on their TAI value after conversion into percentage. Farmers having TAI between $0-33 \%, 34-66 \%$ and $67-100 \%$ was categorized into low adoption, medium adoption and high adoption, respectively. In total, about $47 \%$ farmers fell under medium category adopters followed by high adopters (30\%) and low adopters (23\%). Similar trend of results was found in OR sites where sharing percentage was less in low adopters (8\%) and greater in high adopters $(39 \%)$. However, in non-OR sites higher proportion of farmers (41\%) fell under low adopter's category. Chi-square test shows the significant difference $\left(\chi^{2}=24.82\right.$ and $\left.\mathrm{P}=0.000\right)$ in number of farmers in different adoption categories between OR and non-OR sites (Table 5). Results indicates OR sites are playing important role for increasing more number of high adopter farmers compared to non-OR sites farmers. Timsina et al (2012b) also calculated TAI for rice in Terai condition and reported $96 \%$ farmers fell under medium category adopters while only $4 \%$ fell under the low adopters. Incorporation of improved technical inputs with farmer's participation including extension, community based organization and progressive farmers group is vital to achieve demand oriented output of outreach research program for reducing poverty of farming community (Shrivastava, 2005). Prasad and Karki (2000) reported that multiplication of the technologies at OR sites has vital role in disseminating the technologies. 
Table 5. Percentage of technology Adoption categories by OR and non- OR sites

\begin{tabular}{llll}
\hline Adoption categorization & OR site $(\mathbf{n}=\mathbf{7 0})$ & Non OR site $(\mathbf{n}=\mathbf{7 9})$ & Overall $(\mathbf{n = 1 4 9})$ \\
\hline Low adoption $(0-33 \%)$ & 8 & 41 & 23 \\
Medium adoption $(34-66 \%)$ & 53 & 40 & 47 \\
High adoption $(67-100 \%)$ & 39 & 19 & 30 \\
Total & 100 & 100 & 100 \\
\hline
\end{tabular}

Note: Pearson Chi-square 24.82, $\mathrm{df}=2, \mathrm{P}=0.000$

To examine the reason that are contributing to obtain higher TAI in OR sites, we further analyzed on knowledge and access over different technological aspects between OR and non-OR sites. The knowledge on good agriculture management was found significantly higher in outreach site than non-outreach site $(\mathrm{P}=0.001)$. Access to modern improved seed, and use and availability of agricultural information was found higher in outreach sites compared non-outreach site. These variables were found significant at $5 \%$ level of significance. The availability of agri. inputs and loan was also more on outreach site than non-OR sites. In case of labor availability, there was no significant difference among two sites (Table 6). More knowledge and access on different technological aspects in OR sites might be due to its presence in accessible areas, opportunity to participate in different training program and more organizations/institutions were involved in this area. The outreach research is method of participatory technology development and dissemination which involves interactive participation of farming communities and diverse $\mathrm{R}$ and $\mathrm{D}$ actors from public, private and civil society which provides a service or advice to people in the community, especially those who cannot or are unlikely to come to an office for help (Paudel et al; 2007 and ORD, 2000). It is found that those who have strong linkage at OR site serve their function to deliver technologies to the clienteles with strong commitments and those with poor linkage with weak commitment (Paudel, 2011). Farmers at OR sites adopting technology rapidly compared to non-outreach sites and are getting additional income at outreach site (Timsina et al; 2012a; Timsina et al; 2012b; Shrestha et al; 2012). SARPOD (2012) reported the significance of outreach site of NARC for adoption of modern varieties of wheat in Nepal. Paudel et al (2007) highlighted the importance of outreach research for up scaling of agro-technology through participatory outreach research in Nepal. There have been a number of technologies have been up scaled through OR and some of them helped reduce poverty in Nepal as a result of massive dissemination in farmers field (Paudel and Thakur, 2008). However, outreach research sites should not only focused on varietal testing for different crops, but also focus on crop and resource management aspect, considering integrated approach of crops, livestock, forestry and natural resources, which can cover a wide range of problems being faced by farmers (Shrivastava and Yadav, 2000). Ali et al (2013) reported the importance of agricultural extension services in promoting adoption of improved agricultural technologies like laser 
levelling and improved wheat varieties, and receipt of agricultural extension services was associated with higher wheat yields in Pakistan.

Table 6. Analysis of different aspects of technology between OR and non- OR sites $(\mathbf{n}=\mathbf{1 7 0})$

\begin{tabular}{llll}
\hline \multicolumn{1}{c}{ Description } & \multicolumn{1}{c}{ Chi-square value } & \multicolumn{1}{c}{ P-value } \\
\hline Access to modern improved seed & 9.37 & $0.002^{*}$ & \\
Easy availability of labour & 0.38 & 0.534 & \\
Availability of loan & 2.72 & 0.099 & $0.001^{* *}$ \\
Knowledge on good agriculture management & 10.27 & & \\
Use and availability of agri-information & 5.60 & $0.018^{*}$ & \\
Availability of Agri- inputs & 3.49 & 0.062 & \\
\hline
\end{tabular}

Note: $* * \& *$ Means significant at $1 \%, 5 \%$ level of significance, respectively

\section{Conclusion}

Wheat is the third most important cereal, contributing $20 \%$ of total cereal production. Area covered by modern varieties released after 1990s was about $32 \%$ in the study area. Among the modern wheat varieties, Nepal 297 was still a dominant variety covered $64 \%$ of wheat area in terai of Nepal. The finding indicates that yield of Nepal 297 was relatively higher than other varieties. However, other varieties such as Gautam, Vijaya were also providing more or less same yield compared to Nepal 297 in the study area. Rate of adoption of varieties such as Gautam and Vijay is gradually increasing which are also suitable for late sowing condition as Nepal 297 and which could minimize the risk of yield reduction due to outbreak of disease. The TAI for wheat was found higher (0.63) in OR site compared to non-OR site (0.43). A result indicates more number of wheat farmers in OR sites were using entire cropping system based package of practices compared to non-OR site. OR site were playing significant role for increasing the number of high category adopters compared to non-OR site. However, there is still scope for yield improvement in OR site as well. The knowledge on good agricultural management, access to modern improved seed, and use and availability of agricultural information was found contributing factors to increase TAI in outreach site than non-outreach site. This indicates an increase role of outreach research activities to be strengthened and promoted by NARC and other concerned agencies and stakeholders both from public and private sectors. Activities implemented in outreach sites of NARC are if replicated by other related institutions then it may help in raising awareness level of farmers and eventually contribute in mass adoption of cropping system based package of technology rather than component technology. Therefore, advancement of coordination through strengthening coordination and linkage among the related stakeholders at different level are suggested for promoting 
system based technology dissemination rather than component technology that can contribute to substantial increase in wheat production among the farmers at large.

\section{References}

Agricultural Information and Communication Center (AICC). 2015. Krisi Diary 2072. Agricultural Information and Communication Center (AICC), HariharBhawan, Lalitpur.

Ali, A and DB Rahut. 2013. Impact of agricultural extension services on technology adoption and crop yield: Empirical evidence from Pakistan. Asian Journal of Agricultural and Rural Development 3 (11), Pp. 801- 812.

Ceccarelli, S and S Grando. 2007. Decentralized-participatory plant breeding: an example of demand driven research. Euphytica 155(3), Pp 349-360.

Communication, Publication and Documentation Division (CPDD). 2014. Released and Registered Crop Varieties in Nepal (1960-2013). Nepal Agricultural Research Council (NARC), Communication, Publication and Documentation Division, Khumaltar, Lalitpur, Nepal

FAOSTAT. 2001. Crop Water Information: Wheat. Access from http://www.fao.org/nr/water/cropinfo_wheat.html.

Freeman, HA. 2001. Comparison of farmer-participatory research methodologies: case studies in Malawi and Zimbabwe. Working Paper Series no. 10. PO Box 39063, Nairobi, Kenya: Socioeconomics and Policy Program, International Crops Research Institute for the Semi-Arid Tropics. Pp. 28.

Evenson, RE and D Gollin. 2003 (Editors). Crop variety improvement and its effect on productivity. The impact of international agricultural research. CABI Publishing, UK.

Gauchan, D and SP Pandey. 2005. NARC visions and outreach research strategy for agricultural technology development in addressing poverty and sustainable livelihoods. In: Proceeding of the $7^{\text {th }}$ National Outreach Research Workshop held from 24-25 June, 2004. Nepal Agricultural Research Council, Outreach Research Division, Khumaltar, Lalitpur, Pp, 1-6.

Gauchan, D; M Joshi; and S Biggs. 2003. A Strategy for Strengthening Participatory Technology Development in Agricultural and Natural Resources Innovations Systems. The case of Nepal. International Journal of Technology Management and Sustainable Development, 2 (1), Pp39-52.

Gauchan, D. 2008. Reforming Research and Extension Systems in Nepal: Emerging Models of Technology Development and Transfer. Agricultural Development Journal. 4 (4), Pp 34-44. Nepal 
Government of Nepal/ Ministry of Health and Population (GoN/MoHP). 2011. Nepal Population Report. Government of Nepal, Ministry of Health and Population, Population Division, Ramshahpath, Kathmandu, Nepal.

Joshi, GR. 2010. Factors influcing the adoption of fertilizer technology among rice farmers in the Terai region of Nepal. SAARC Journal of Agriculture, 8 (1), Pp 21-32.

Ministry ofAgriculture and Cooperative/Department of Agriculture (MoAC/DoA). 2009.

Krisi Diary. Ministry of Agriculture and Cooperative/Department of Agriculture/Agriculture information and Communication centre, Hariharbhawan, Lalitpur

Ministry of Agriculture and Cooperative (MoAC). 2009. Statistical information on Nepalese Agriculture. Published by Government of Nepal, Ministry of Agriculture and Cooperative/Agribusiness Promotion and Statistics Division, Singhdurbar, Kathmandu, Nepal.

Ministry of Agriculture Development (MoAD). 2014. Statistical information on Nepalese Agriculture. Published by Government of Nepal, Ministry of Agriculture Development /Agribusiness Promotion and Statistics Division, Singhdurbar, Kathmandu, Nepal.

Morris, ML; HJ Dubin; and T Pokhrel. 1994. Returns to wheat research in Nepal. CIMMYT Economics Working Paper 92-04. Mexico, D.F.: CIMMYT.

McIntyre, BD; HR Herren, J Wakhungu, and RT Watson. 2009. Agriculture at a crossroads. A Synthesis of the Global and Sub-Global International Assessment of Agricultural Knowledge, Science and Technology for Development (IAASTD) Reports. Island Press, Washington, DC. Pp. 71-74.

National Wheat Research Program (NWRP). 2014. Annual Report 2013-14. Published by National Wheat Research Program, Bhairahawa, Rupandehi, Nepal.

Outreach Research Division (ORD). 2000. Proceeding of Fifth National Outreach Research Workshop, 30-31 May, 2000. Published by Nepal Agricultural Research Council, Outreach Research Division, Khumaltar, Lalitpur

Outreach Research Division (ORD). 2009. Annual Report (2008/09). Outreach Research Division, Khumaltar, Kathmandu, Nepal

Ponzio, C, R Gangatharan; and D Neri. 2013. The potential and limitations of farmer participatory research in organic agriculture: A review. African Journal of Agricultural Research, 8 (32), Pp 4285-4292.

Paudel, MN; RP Upreti; and R Khadka. 2007. Up scaling of agro-technology: A concept of participatory outreach research in Nepal. In: proceeding of the $8^{\text {th }}$ National Outreach Research Workshop held from 19-20 June, 2007. Published by Nepal Agricultural Research Council, Outreach Research Division, Khumaltar, Lalitpur, Pp.1-9. 
Paudel, MN; and NS Thakur. 2008. Achievements of outreach research for agrotechnology generation and transfer: An experience of Nepal. SAARC Journal of Agriculture, 6 (1), Pp. 1-9.

Paudel, MN. 2011. Outreach researche a bridge between research and extension. In: proceeding of the National Outreach Working Group Workshop held on 19 May, 2011. Published by Nepal Agricultural Research Council, Outreach Research Division, Khumaltar, Lalitpur, Pp, 4-13.

Paudel, MN. 2013. Outreach Research: A liaison between research and extension. Agronomy Journal of Nepal (Agron JN) 3, Pp 97-108.

Prasad, RB and TB Karki. 2000. Outreach research programme at Lumle and its future strategy. In: Proceeding of the $5^{\text {th }}$ National Outreach Research Workshop held from 30-31 May, 2000. Nepal Agricultural Research Council, Outreach Research Division, Khumaltar, Lalitpur, Pp, 74-82.

Shrestha, B; B Sharma; NS Thakur; R Khadka; HP Pathak; YR Bhusal; and KB Thapa. 2012. Impact assessment of Outreach site of Bharatpokharai, Kaski, Nepal. In: proceeding of the 10th National Outreach Research Workshop held from 27-28 February, 2012. Published by Nepal Agricultural Research Council, Outreach Research Division, Khumaltar, Lalitpur, Pp, 365-372.

Shrestha, HK; HK Manandhar; and PP Regmi. 2012. Variety Development Cost versus Variety Adoption in Major Cereals in Nepal. Nepal Journal of Science and Technology, 13 (1), Pp.7-15.

Shrestha, HK; HK Manandhar; and PP Regmi. 2013. Investment in Wheat Research in Nepal - An Empirical Analysis. Agricultural Economics Research Review, 26 (2), Pp 221-228.

Shrivastava, AC and RB Yadav. 2000. Outreach research:Problems and Prospectus. In: Proceeding of the $5^{\text {th }}$ National Outreach Research Workshop held from 30-31 May, 2000. Nepal Agricultural Research Council, Outreach Research Division, Khumaltar, Lalitpur, Pp, 64-73.

Shrivastava, AC; JB Prasad; and SN Kurmi. 2005. Verification and dissemination of technologies through outreach research. In: Proceeding of the $7^{\text {th }}$ National Outreach Research Workshop held from 24-25 June, 2004. Nepal Agricultural Research Council, Outreach Research Division, Khumaltar, Lalitpur, Pp, 82-88.

SARPOD. 2014. Annual Report (2013/14). Socioeconomics and Agricultural Research Policy Division, NARC, Khumaltar, Lalitpur, Nepal.36p.

SARPOD. 2012. Annual Report (2011/12). Socioeconomics and Agricultural Research Policy Division, NARC, Khumaltar, Lalitpur, Nepal.18p. 
The Himalayan Times. 2007. Yellow rust resistant wheat variety released. Published on November 24, 2007.

Timsina, KP; KP Shrestha; and S Pandey. 2012a. Factors affecting adoption of new modern varieties of Rice in eastern Terai of Nepal. In the proceeding of 4th Society of Agricultural Scientist-Nepal (SAS-N) conference held at Lalitpur 4-6 April, 2012. Published by Nepal Agricultural Research Council (NARC) \& Society of Agricultural Scientists (SAS-N), Nepal, Pp 48-54.

Timsina, KP; HB Bista; D Gauchan; B Sapkota; YN Ghimire; KP Shrestha; and B Shrestha. 2012b. Adoption Analysis of Rice Varieties in Terai of Nepal. In the proceeding of $10^{\text {th }}$ National Outreach Research Workshop held at Regional Agricultural Research Station, Lumle, from February 27-28, 2012. Published by Nepal Agricultural Research Council (NARC) \& Outreach Research Division (ORD), Khumaltar, Nepal.

Vaidya, SN. 1996. NARC Outreach Research: An overview. In: Proceeding of third National Outreach Research Workshop, 21-23 May, 1996. Published by Nepal Agricultural Research Council, Outreach Research Division, Khumaltar, Lalitpur

Wettasinha, C; A Waters-Bayer; L van Veldhuizen; G Quiroga; and K Swaans. 2014. Study on impacts of farmer-led research supported by civil society organizations. Penang, Malaysia: CGIAR Research Program on Aquatic Agricultural Systems. Working Paper: AAS- 2014-40.

Witcombe, J; KK Lal; and KD Joshi. 2009. Scoping study on adoption of rice varieties from client oriented breeding in the Nepal rice innovation system. CAZS natural resources, Bangor University, UK. 